\title{
La imagen social de la femineidad y masculinidad en la enseñanza secundaria en Chile
}

\section{The social image of femininity and masculinity on secondary schools in Chile}

\author{
Graciela Raquel Ezzatti San Martin*
}

\begin{abstract}
RESUMEN
La imagen social sobre femineidad y masculinidad de los/las jóvenes estudiantes de enseñanza secundaria Chilena se relaciona directamente con las relaciones de pareja que establecen. Lamentablemente en Chile la violencia de género es una práctica comprendida como cotidiana y donde se espera que las mujeres sean sumisas a la voluntad masculina. Si se comprende cual es la imagen social que emana de la masculinidad y femineidad se podrá tener pistas certeras del origen de la violencia en las relaciones de pareja. El articulo pretende describir el análisis sobre la imagen social femenina y masculina de estudiantes de enseñanza secundaria en sus relaciones cotidianas en los establecimientos educacionales Chilenos de todos los niveles socioeconómicos. El artículo se realizó como parte de la investigación titulada: Estudio de las representaciones sociales de género en las interacciones educativas de los/las profesores y los/las estudiantes de educación secundaria.

Palabras-clave: imagen social; femineidad; masculinidad; violencia; género.
\end{abstract}

\begin{abstract}
The social image of Male and Female young students in Chilean secondary education is directly related to the couple relationships they establish. Unfortunately, in Chile gender violence is a daily practice and women are expected to be submissive to the male's will. If one understands which

* Psicóloga Clínica. Magíster en la Universidad Metropolitana de Ciencias de la Educación
\end{abstract} - Santiago/Chile. 
social images emanate from masculinity and femininity, then one will be able to find out the origins of violence in couple relationships. The article analyses femininity's and masculinity's social images of secondary students in their couple relationships in Chilean educational establishments of all socioeconomic levels. This text is part of an investigation titled: Study of social and gender representations in educative interactions between teachers and students of secondary education.

Keywords: social image; female; male; violence; gender.

Es importante tener en cuenta que la construcción de la identidad de género es determinante de las relaciones entre mujeres y hombre, no es extraño que la idea de femineidad y masculinidad que se representa en el cotidiano social esté incidiendo en las conductas de abuso de poder de los hombres sobre las mujeres. Los modelos de femineidad y masculinidad entregados en la interrelación educativa desde las/los profesores hacen las/los estudiantes favorecen las debilidades o fortalezas de la formación moral, social, afectiva y ciudadanas de las/los estudiantes. En este sentido si los modelos que se explicitan en las prácticas educativas pueden hacer el cambio hacia relaciones entre hombres y mujeres más complementarios y pacíficas.

A partir del análisis de la imagen social femenina de las adolescentes que estudian enseñanza secundaria en Chile; se puede señalar que la imagen social de mujer esta relacionada con el arreglo personal, su cuerpo debe destacar los atributos femeninos como forma de instalarse en una sociedad que indica a las mujeres con determinadas imágenes de belleza. Una joven profesora de establecimiento de nivel socioeconómico bajo da un ejemplo en su cita. Sí, arreglarme más, pintarme, comprarme distinta ropa, ropa más bonita, más ajustadita... Sin embargo la imagen femenina de belleza entra en contradicción con el desempeño proactivo en otras áreas como la laboral o social. En ese sentido, este estudio coincide con los hechos por Palma (2002) que dicen que entrar al mundo de la femineidad propone adquirir un estatus de belleza que va incluido al ser mujer y que puede entrar en tensión con los roles de la vida diaria.

En este estudio se pudo asociar a la femineidad la imagen social de "cahuineras". Tal cual lo expresa una chica que estudia en un establecimiento educacional de nivel socioeconómico alto: Con las mujeres no me llevo тиy bien, son cahuineras, cosas así. En términos populares, dicho de otra forma, la femineidad carga con el estigma de la insidia inherente a su condición. Todos los estigmas asignados al género femenino son una forma de asegurar un lugar de inferioridad natural para estas. Estas vivencias se van instalando en la mente femenina desde la infancia mas temprana, se va aprendiendo he instalando en el inconsciente colectivo y se manifiesta en las criticas que los hombres y las 
propias mujeres hacemos de nosotras mismas. El aprendizaje de mujer "cahuinera", "chusma", "lleva y trae", "intrigante" y "manipuladora" se aprende cuando se instala la función simbólica de lo femenino al momento que se adquiere el lenguaje. Este estudio coincide con los hechos por Alcalay y Milicic (1994) respecto a cuando se instalan estos estigmas y como también coincide con los trabajos de Lagarde (1990) que asegura a la mujer como sujeto que carga con múltiples estigmas en distintos momentos de su vida, los va adquiriendo y se agudizan según el desempeño social que esta tenga. Lo interesante es saber que los estigmas como los describe Goffman (1985) se basan en prejuicios irracionales e inconscientes acerca de un atributo desacreditable del sujeto que permite a los otros discriminarlos o dañarlos por cargar con este y por sus características la estigmatización cruza todas las clases sociales y todas las culturas.

Siguiendo la línea del tema que se viene tratando, otra imagen que se le atribuye como representación social a la mujer desde niña es la agresividad. Esta nueva estigmatización de las mujeres, es un fenómeno digno de reflexión puesto que para el imaginario popular las mujeres deben poseer un alto nivel de sensibilidad, ternura y amabilidad, sin embargo, cuando las mujeres o niñas intentan declarar sus intereses o no aceptan alguna forma de sumisión entonces la imagen que la sociedad propone de estas es la de "agresivas"; nuevamente este estudio coincide con el de Lagarde (1990). Por otra parte, se espera que lo que respondan las mujeres sea una respuesta de sumisión y si esta respuesta varia entonces la mujer es sancionada como agresiva por la sociedad educativa o de la cual se trate. Lo interesante consiste que estas imágenes sociales pueden estar en la génesis del maltrato que lleva al femicidio, puesto que, se le atribuyen a las mujeres cualidades contradictorias como lindas, frágiles en tensión con cahuineras y agresivas. Se supone que las mujeres deben ser lindas, frágiles y sumisas en sus relaciones de pareja. Cuando estas intentan tan solo demostrarse como personas reales, los hombres pertenecientes al grupo masivo del machismo hegemónico sancionan a las mujeres en distintas formas de maltrato que puede llegar hasta la muerte.

En la investigación una de las formas de recopilación de información fueron los grupos de discusión entre adolescentes de tercer año secundario de los establecimientos estudiados; la información allí recogida es completamente coincidente con las que emitió en las entrevistas. De esta manera los/las jóvenes señalan claramente que para ser femenina se debe ser sutil, delicada, además las mujeres deben resaltar sus atributos de belleza por medio de la ropa o la pintura. Se debe señalar que estas citas corresponde a una estudiante del establecimiento de nivel socioeconómico bajo, la que señala: 
Yo creo que una mujer femenina, de verdad femenina [...] va en lo sutil, en las cosas que uno ve y uno piensa y uno dice esto es femenino y creo que no han cambiado mucho que por ejemplo ser delicada, ser sutil, hablar amable, eso denota el feminismo pero ahora también otra cosa como [...] es femenina por su ropa $[\ldots]$.

Este estudio permite señalar que la estigmatización femenina sigue estando vigente en la imagen social femenina actual, lo que corrobora los estudios de Goffman (1985) y los de Palma (2002) el primero respeto a la estigmatización femenina que cruza todas las clases sociales y la segunda a la tensión entre el femenino sutil y frágil opuesto a mujer persona con derechos y necesidades.

Asimismo, se puede afirmar que están emergiendo otros contenidos de imagen social en la juventud. En la actualidad se puede apreciar que los jóvenes hombres y mujeres de los establecimiento educacionales están construyendo una imagen social diferente de femineidad, este responde mas claramente a las necesidades de respeto de las mujeres. También reconocen varios tipos de femineidad que no son excluyentes y pueden apreciar que estos tipos de femineidad convivan. Además los y las jóvenes aceptan una proactividad sexual tanto en el discurso como en los hechos de las mujeres jóvenes. Los estudios hechos por Palma (2002) coinciden con estos hallazgos. Las afirmaciones de las citas posteriores avalan estos dichos. De esta forma un joven estudiante de un establecimiento de nivel socioeconómico bajo afirma:

Yo creo que ha cambiado en las actividades en los derechos, antes uno veía una mujer jugando fútbol [...] y decía que onda!! Esta loca [...] ahora es mas normal Hoy en día la femineidad seda entre mujer y mujer, la femineidad ha cambiado de concepto [...] por ejemplo ahora varia entre mujer y mujer [...] la forma de ser femenina de Antonia, es súper diferente de ser de la Javi, pero no por eso ella es mas femenina que ella, ahora la femineidad se expresa de distintas formas.

Es interesante descubrir que las estudiantes del establecimiento de nivel socioeconómico alto, señalan que sus madres han contribuido a formar en ellas otro estilo de femineidad, sin embargo se sienten estigmatizadas porque no siempre se las reconoce como femeninas si no asumen las actitudes tradicionales que se esperan de una mujer. Se entiende que la actitud de tomar cerveza por la botella es típico de los varones y es mal visto en mujeres; cuando estas optan por usar estilos atribuidos a hombres reciben una sanción social que termina por 
generarles molestia. Sin embargo agradecen las nuevas opciones que entregan las madres respecto a femineidad. La imagen social femenina continua siendo la de la sutil y frágil joven bella, las que se atreven a salirse de estos cánones serán no reconocidas como femeninas o tildadas de masculinas o "amachadas". Estos hallazgos coinciden con los estudios de Jodelet (1984) en cuanto a la naturalización de la representación social y con los estudios de Bourdieu (2000) respecto a normalización de las conductas según el género. La siguiente cita ejemplifica los dichos precedentes.

Yo creo que cuando mas molesta, cuando tu sabi que tienes una postura femenina y te trata de no lo eres, mi madre me ha enseñado a no ser tan femenina, cuando yo quiero hacerlo, cuando vamos a una plaza a tomarnos una cerveza no andamos pidiendo vaso a donde nos empinamos la chela y mis papas lo saben y ellos son consiente de todo lo que hago, tenemos una buena comunicación.

Es de destacar las siguientes representaciones sociales de Femineidade - las mujeres son cahuineras y las mujeres deben ser delicada, ser sutil. Estas dos representaciones sociales son como las dos caras de una moneda. En los grupos de estudiantes entrevistados así como profesores y profesoras, cuando se trata cualquier tema femenino en algún momento de la conversación aparecen uno o los dos contenidos como inherentes a la femineidad. Este tipo de tensión vivencial entre el deber ser y lo que parece ser esta documentado en chile por Palma (2002), en Norte América por Lagarde (1990) y en Europa por Braidotti (2004). Este tipo de tensión entre la "mujer que debe ser" y "la mujer que es" genera en los varones una suerte de desconcierto persecutorio por el cual podría reaccionar violentamente, al darse cuenta que el deber ser femenino que le inculcaron mediante la educación no existe, solo existe el ser real del objeto de amor. Es por ello que la cultura, la sociedad y la educación deben acercar estos contenidos hasta llegar los contenidos de femineidades reales que distan mucho de estas representaciones.

Por otra parte la imagen social de masculinidad continúa manteniéndose con los viejos cánones hegemónicos, al respecto el entrevistado profesor del establecimiento de nivel socioeconómico bajo, indica que la agresividad, fuerza física y demarcar territorio son actitudes típicas de sus estudiantes hombres. Estos hallazgos coinciden con los de Olavarria (2001) y Connell (2003), estos estudiosos de la masculinidad coinciden con que esta marca ciertos mandatos que los hombres deben cumplir de acuerdo a su cultura y a su época. Se nota 
que en este establecimiento los mandatos de la masculinidad hegemónica son aceptados y ejecutados para adquirir el derecho al género. Se debe destacar que cuanto mas bajo es el nivel socioeconómico, mas rígido son los mandatos para demostrar masculinidad.

Se pudo notar que las mujeres jóvenes del establecimiento de nivel socioeconómico alto, tiene una concepción de masculinidad más amplia ligada con los movimientos que se dan al interior de las tribus urbanas, donde la sexualidad se amplia y se aceptan en algunas de estas, un tipo de masculinidad mas andrógina; para estas jóvenes existe una imagen social de masculinidad y juventud amplia que puede aceptar la diversidad masculina. Aunque las jóvenes reconocen que en su círculo existen chicas que todavía mantienen intolerancias hacia la masculinidad homosexual. Las próximas citas indican estos hallazgos.

Bueno, es cada vez más mujer para mi gusto. O sea no, se viste normal. O sea no que normal hombre, porque es de un grupo... él es de un estilo jarco, emo, y todos se visten así. No es necesariamente ser gay, pero al escucharlo es como escuchar una mujer más.

[...] yo llegué en séptimo acá al colegio y l estaba y lo molestaban que era maricón, que era gay, que era pa las mujeres, que le gustaban los hombres. Pero ahora $[\ldots]$ y es más, ahora que lo asumió que el curso sabe que es gay, lo molestan mucho menos que antes.

En el establecimiento de nivel socioeconómico medio se corroboran las imágenes sociales de masculinidad hegemónica que tiene los hombres del establecimiento de nivel socioeconómico bajo, considerando la fuerza y la violencia como un atributo masculino. La diferencia se establece en esta ocasión porque son mujeres jóvenes estudiantes quienes dicen que los hombres son violentos y que se abusan de su fuerza en sus palabras - se pasan pa la punta. Estas afirmaciones son relevantes porque estarían demostrando que el abuso de poder y la desigualdad que avala el maltrato hacia las mujeres se estaría ejerciendo en los establecimientos de enseñanza media de nivel socioeconómico medio al menos. Las citas recopiladas a través del foco group así lo demuestran:

$[\ldots]$ el hombre tiene mas fuerza $[\ldots]$

[...] y lo hombres se aprovechan de uno, porque son mas agresivos! 
Ahí po donde son agresivos es ahí donde matan Mujer c: Ahh [...] es porque trabajan y se creen $[\ldots]$

La imagen social de masculinidad en el establecimiento de nivel socioeconómico bajo, está vinculada con la virilidad y la potencia sexual, tanto para jóvenes mujeres como para varones. Entre los hombres jóvenes que estudian allí existe una necesidad de reafirmar su masculinidad a través de cierto tipo de violencia física. Pero debe de estacarse que ellos consideran que es "estúpido" aquel que debe reafirmar su potencialidad masculina a través de la fuerza. No molestándole tanto la tener que demostrar virilidad para ser varón. Se puede señalar que si bien en este establecimiento la masculinidad sigue asociada al poder físico, ostentaciones sexuales de machismo y violencia física, clásicas de la masculinidad hegemónica, los jóvenes varones que estudian allí empiezan a afirmar que esas demostraciones de masculinidad se alejan de el estilo inteligente de masculinidad que quieren tener; esta imagen se grafica en la frase "generalmente el más estúpido es mas macho". Una de las afirmaciones de mujeres y varones estudiantes aquí recopiladas por medio del foco group así lo indican: "La mayor característica de la masculinidad [...] es que es mas importante para los hombres que para las mujeres, o sea para un hombre es más importante ser masculino".

La imagen social de masculinidad también esta ligada a ciertas libertades sexuales que aseguran la condición masculina a partir de las observaciones en el establecimiento de nivel socioeconómico bajo. Se pudo notar que un varón acariciaba a sus compañeras y estas asumían estas caricias sumisamente como parte de un ritual, la expresión activa de la sexualidad masculina da estatus al varón que la demuestre. Las mujeres en actitud pasiva y receptiva avalan la condición masculina del sujeto acariciador. Este hallazgo coincide con los de Olavarria (2005) quien sostiene que el hombre para obtener su condición debe conquistar a una mujer y esta debe ser aval de tal conquista. Las expresiones de afecto expresadas indiscriminadamente al menos a tres chicas que se pudieron captar mediante la observación corrobora estos dichos: Hombre, se acerca a mujer la abraza y la acaricia. A las tres amigas el hombre las acarició.

Estas representaciones sociales sobre masculinidad tienen un denominador común, que tanto, estudiantes mujeres, profesores y los mismos estudiantes hombres tienen una imagen social de masculinidad como agresiva y violenta a través de la fuerza física. Todas estas características dejan al joven de hoy con un perfil de masculinidad hegemónica de preferencia. Si bien todos los grupos sociales participantes en la investigación señalan cambios en la masculinidad, suelen centrar su imagen masculina en los dos polos - la masculinidad domi- 
nante macho agresivo o la masculinidad excluida "varón homosexual". Las otras masculinidades en la enseñanza secundaria se vuelven invisibles para la cultura educativa en general.

La investigación reviso la imagen social en relación a poder y distinguió que el poder de la sexualidad se destaca como arma de retención de las estudiantes hacia los varones, la profesora del establecimiento de nivel socioeconómico bajo decía que las charlas de las estudiantes se referían a que a través de sexo podían retener a sus pololos. Estas representaciones sociales de poder mediante el sexo son coincidentes con el marco teórico foucaultiano, quien afirma que el sexo es un elemento potente de extensión del poder.

Otro elemento de poder es el lenguaje. La profesora participante considera que el lenguaje es un instrumento de marcar poder entre pares. Este hallazgo es coincidente con los dichos de Foucault (1979) quien afirma que el poder circula en el discurso de los sujetos. Las relaciones de poder que circulan por medio de los discursos de los sujetos en las relaciones de pareja estarían marcando la génesis de la violencia psicológica o simbólica. La siguiente cita lo corrobora: Sí, yo siento como que de repente tienen los cabros tienen un vocabulario que es el de ellos, entre pares, que en algún minuto utilizan con uno en términos que se pierden un poco el límites... mujeres y hombres.

Por otra parte en el establecimiento de clase socioeconómica alta el profesor participante hace otro aporte al contenido de imagen social del poder, indicando la idea de posesión. Este hallazgo se convierte en básico para esta investigación, desde la economía capitalista los sujetos han entrado en la dinámica de poseer todo cuanto puedan como símbolo de poder, uno de los elementos que hace más poderoso al hombre en general, al decir de Olavarria (2004) es conquistar y "poseer" a una mujer. Esta posesión sexual se convierte en posesión material y la relación de poder del sujeto hombre se torna violenta cuando la mujer pretende ser sujeto no objeto de la pareja. Es corriente escuchar a los hombres hablar de la pareja en términos de "mi mujer" como si se estuvieran refiriendo a otro bien (objeto material). Esta confusión afectiva, mental que se establece en las relaciones de pareja se va aprendiendo desde temprano en la educación formal e informal. Cuando en la relación de pareja se termina la fase de conquista, el sujeto hombre cree haber adquirido una mujer para su uso, si la sujeto mujer no se opone a este trato entonces la relación podría persistir con un costo afectivo social y físico alto para la mujer. Si esta se opone a ser tratada como objeto también el costo de la liberación es alto pero se recobraría como sujeto, como ser en sociedad libre de dar y recibir amor.

En los focos group del establecimiento educacional de nivel socioeconómico medio, existe confusión y perplejidad frente al tema de la violencia extrema de pareja que lleva al feticidio. Sencillamente las y los jóvenes no saben a que 
atribuir tal cantidad de violencia mortal, pues tienden a creer que debería estar involucrado el alcoholismo o la drogadicción para que un sujeto matara la pareja que se supone que ama. Las citas posteriores demuestran el desconcierto que genera la violencia en las y los jóvenes.

$[\ldots]$ cuando un hombre mata a una mujer [...] Que para un hombre mate a una mujer $[\ldots]$ yo creo debe ser, no se no se miembro de la casa o tener demasiado rabia contra ella.

Ahí po donde son agresivos es ahí donde matan Mujer [...] Ah... es porque trabajan y se creen $[\ldots]$

Yo una vez conocí a una señora que el marido la mato y el marido no tomaba y se drogaba $[\ldots]$

Igual si uno se educa $[\ldots]$ pero si uno no sabe $[\ldots]$ aunque tenga toda la educación y están enojados o mucha rabia y con alcohol o droga [...]

Se debe señalar que la imagen social de pasarse pa la punta en las relaciones de pareja de las y los jóvenes del establecimiento educacional de nivel medio es un fenómeno a tener en cuenta. Puesto que en medio del juego de la conquista hay una sensación de parte de las féminas de este estudio que indicaría que los hombres que son sus parejas tienden a romper las normas para afianzar su poder sobre estas. Según las afirmaciones de las citas los hombres que se pasan pa la punta, suelen insultarlas (violencia simbolica) o faltarles el respeto (agarrarlas pal leseo). En estos espacios de poder que van ganando los hombres también esta la génesis de la violencia, puesto que se van permitiendo licencias verbales (simbólicas) que se normalizan como representaciones sociales (JODELET, 1984) y que luego son parte del trato abusivo cotidiano. Así lo expresan las jóvenes participantes:

Nos llevamos bien pero a veces los hombres se pasan pa la punta $[\ldots]$

Nos llevamos bien pero algunas veces uno le da un poquito mas de confianza a los hombre si se pasan pa la punta [...] la agarran a garabatos $[\ldots]$ pal leseo $[\ldots]$ 
Es importante señalar como el hombre participante de este foco group del establecimiento de nivel socioeconómico bajo detenta un discurso de naturalización referente al poder, encubriendo en los cambios sociales el sentido de quien debe o puede detentarlo. Parafraseando a Jodelet (1984) este discurso pone al poder como natural y parte de la sociedad por lo cual ni hombres ni mujeres debieran estar preocupados del espacio que el poder proporciona. Dejando entrever un supuesto ideológico falso detrás de un discurso naturalizador. Esta es otra forma de origen del abuso y el maltrato simbólico pretendiendo que los espacios de autoridad no deben estar definido porque todo cambia. Estos hallazgos coinciden con los de Bourdieu (2000) referente a la naturalización y normalización de los espacios de poder de los hombres frente a las mujeres.

Por otra parte los y las estudiantes del establecimiento de clase socioeconómica alta se dan cuenta que algunos profesores usan su poder por intermedio de un discurso que pretende ser gracioso pero en realidad es burlesco donde descargan su poder machista contra las estudiantes de sus clases. Estas afirmaciones nuevamente se confirman en las teorías de Foucault (1979) en cuanto al discurso y al lugar que ocupa el poder en este.

[...] El profe de educación física, por ejemplo, siempre tira la talla, “ las mujeres deben barrer" [...]. Yo por ejemplo con mis compañeras, hemos dejado de hablarle, siempre lo consideramos demasiado sexual, demasiado mirón, son cosas super poco profesional, porque en este mundo uno trata de desenvolverse como persona. Se perturba [...] Una cosa es la confianza y otra es la patudes. Nosotros tenemos una relación de amigos con los profes, pero igual el se va para otro lado $[\ldots]$.

El estudio realizado tuvo como propósito conocer las representaciones sociales de género que emanan de las relaciones educativas entre profesores/ as y estudiantes, considerando que el aprendizaje formal e informal sobre los modelos de relaciones entre mujeres y hombres se aprenden desde la infancia más temprana, se ensayan en la etapa escolar categorías de género y se ejecutan como parte de la vida cotidiana. De esta manera, el propósito antes explicado se enmarco en el dilema de las relaciones inter-género, que demuestra la situación de desigualdad de las mujeres frente a los hombres en las múltiples áreas de la convivencia humana. Así como, las relaciones que existen entre las representaciones sociales de género y la interacción educativa entre profesores/as y estudiantes adolescentes y jóvenes de ambos sexos.

El acercamiento al problema se realizo desde una profundización teó- 
rica multidimensional. Así como, desde un análisis de contenido enmarcado en el enfoque de las representaciones sociales (MOSCOVICI, 1996). Es así, que se pudo comprender que las representaciones sociales inter género están "naturalmente" integradas en las prácticas educativas (BOURDIEU, 2000). De esta manera se considera que el lugar de la mujer ha sido estatuido en el orden social como sucedáneo de aquel que ocupa el hombre. En este sentido en parte esta instalado en el colectivo social como parte de la cotidianeidad y no se cuestiona. En este contexto profesores/as y estudiantes conviven pretendiendo que sus relaciones inter género son "normales" y en ese entendido no existirían conflictos; dentro de estas fantasías de "normalidad" y "naturalidad" empiezan a emerger los conflictos que llevan a las relaciones de desigualdad entre hombres y mujeres.

La permanencia en el tiempo de la institución escuela y sus dinámicas genera la ilusión de naturalidad y cotidianeidad sobre las vidas de los sujetos participantes en la comunidad escolar, alejando cualquier atisbo de cuestionamiento sobre la existencia femenina o masculina. En este sentido, uno de los propósitos de esta investigación, fue revisar las interacciones sociales que emanaron de la convivencia educativa entre profesores/as y estudiantes adolescentes y jóvenes, a fin de seguir los procesos de cambio de las representaciones sociales inter género en estas relaciones. De esta manera y desde la profundización teórica referencial, se afirma que el intercambio verbal, gestual, afectivo, imaginativo y valorico que construyen las y los jóvenes de los establecimientos educacionales, municipal, subvencionado y particular privado; generan un caudal de representaciones sociales a partir de sus relaciones inter género. Estas representaciones sociales mantienen el sistema social imperante, pero también introducen cambios que podrían ser la base de una revolución social a largo plazo.

Desde otra óptica, se debe señalar la importancia de los resultados de esta investigación sustentada en evidencia que emerge a la luz pública desde los medios de comunicación masivos que informan que la desigualdad de la mujer chilena se ha ido transformando en una escalada de violencia física contra mujeres, esposas y madres por parte de sus parejas, con resultados de muerte y que año a año estas aumentan considerablemente. Este conflicto constituye una verdad que las autoridades de gobierno intentan mitigar con políticas de contingencia y mediadas de protección, que han resultado insuficientes. Desde esta perspectiva se debe señalar que los hallazgos y conclusiones de este estudio indican la importancia de las prácticas educativas como regeneradoras de nuevos códigos al interior de las representaciones sociales que podrían permitir reformar los principios ideológicos antes mencionados, sustentándolos en relaciones inter género de respeto a las diferencias individuales, complementariedad y reciprocidad. 


\section{REFERENCIAS}

ALCALAY, Lidia; MILICIC, Neva ¿Qué aprenden las adolescentes sobre género en el sistema familiar? Proyecto Fondecyt 92/799. Santiago, 1994.

BOURDIEU, Pierre. La dominación Masculina. Barcelona: Anagrama, 2000.

BRAIDOTTI, Rosi. Feminismo, diferencia sexual y subjetividades nómades. España: Gedisa, 2004.

CONNELL, Robert. Masculinidades. Mexico: Pueg, 2003.

FOUCAULT, Michel. Microfísica del poder. Buenos Aires: La piqueta, 1979.

GOFFMAN, Ervin. Estigma. Montevideo: CEUP, 1985.

JODELET, Denise. La representación social: Fenómenos conceptos y teoría. In: MOSCOVICI, S. Psicología Social. Barcelona: Paidos, 1984. v. II.

LAGARDE, Marcela. Cautiverio de las mujeres: madresposas, monjas, putas, presas y locas. México: UNAM, 1990.

MOSCOVICI, Sergei. Psicología Social. Barcelona: Paidos, 1996. v. II.

OLAVARRÍA, José. El orden institucional de la educación en Chile, la LOCE y la Educación Sexual. Género, educación sexual, transversalidad y subsidiaridad. In: MENDOZA, Antonieta. Visiones Hispanolatinoamericanas. Santiago: Universidad Metropolitana de Ciencias de la Educación, 2004.

- ¿Hombres a la Deriva? Santiago: FLACSO, 2001.

. La masculinidad y los jóvenes adolescentes. Revista Docencia, v. 27, n. X, p. $65-71,2005$.

PALMA, Irma. Sexualidad, Afectividad y Relaciones de Pareja en los/as Adolescentes en la Sociedad Chilena. Santiago: Universidad de Chile, 2002.

Texto recebido em 8 jun. 2009. Texto aprovado em 10 jul. 2009. 